\title{
Inflammation and Implantation
}

\author{
Nava Dekel ${ }^{1}$, Yulia Gnainsky ${ }^{1}$, Irit Granot ${ }^{1}$, and Gil Mor ${ }^{2}$ \\ ${ }^{1}$ Department of Biological Regulation, the Weizmann Institute, Rehovot, Israel \\ 2 Department of Obstetrics and Gynecology and Reproductive Science, Yale University School of \\ Medicine, New Haven, CT, USA
}

\begin{abstract}
Approximately half of all human embryo implantations result in failed pregnancy. Multiple factors may contribute to this failure, including genetic or metabolic abnormalities of the embryo. However, many of these spontaneous early abortion cases are attributed to poor uterine receptivity. Furthermore, although many fertility disorders have been overcome by a variety of assisted reproductive techniques, implantation remains the rate-limiting step for the success of the in vitro fertilization (IVF) treatments. It has been demonstrated that endometrial biopsies performed either during the spontaneous, preceding cycle, or during the IVF cycle itself, significantly improve the rate of implantation, clinical pregnancies and live births. These observations suggest that mechanical injury of the endometrium may enhance uterine receptivity by provoking the immune system to generate an inflammatory reaction. In strong support of this idea, we recently found that dendritic cells (DCs), an important cellular component of the innate immune system, play a critical role in successful implantation in a mouse model. In this review, we discuss the hypothesis that the injury-derived inflammation in the biopsy-treated patients generates a focus for uterine DCs accumulation that, in turn, enhances the endometrial expression of essential molecules, which facilitate the interaction between the embryo and the uterine epithelium.
\end{abstract}

\section{Keywords}

Dendritic cells; implantation; inflammation; pregnancy

\section{The uterus and implantation}

Embryo implantation, which is an absolute requirement for reproduction, starts with blastocyst apposition to the uterine endometrium, followed by its attachment to the endometrial surface epithelium. Implantation can only take place in a receptive uterus. In humans the uterus becomes receptive during the mid-secretory phase (days 19-23) of the menstrual cycle, commonly known as the window of implantation (WOI). Rodents exhibit a relatively short (4 days) estrous cycle and develop a receptive uterus on day 4 after mating. ${ }^{1}$

The uterine endometrium consists of two distinct cellular components, the stromal cells and the cells of the epithelium. The cellular changes during the WOI include the transformation of the fibroblast-like endometrial stromal cells into larger and rounded decidual cells (decidualization), ${ }^{2}$ as well as the growth and development of secretory glandules and the emergence of large apical protrusions (pino-podes) and microvilli on the luminal epithelium.

Correspondence: Gil Mor, MD, PhD, Department of Obstetrics, Gynecology \& Reproductive Sciences, Reproductive Immunology Unit, Yale University School of Medicine, 333 Cedar St. LSOG 305A New Haven, CT 06520, USA. gil.mor@yale.edu. 
${ }^{3}$ In parallel, modulations in the expression of different cytokines, chemokines growth factors, and adhesion molecules take place. ${ }^{2,3}$ These changes are subjected to regulation by the ovarian steroid hormones, 17 beta-estradiol and progesterone. ${ }^{4,5}$

The modulated expression of the above-mentioned molecules at the WOI provides circumstantial evidence for their role in this process. However, the association of some of these specific endometrial genes with impaired fertility in humans has not been consistent. 5,6 Moreover, global microarray analysis employed in search of implantation markers revealed a large number of genes expressed differentially in human endometrium during the WOI, ${ }^{7-10}$ providing correlative evidence for their possible involvement in implantation. However, their specific function has yet to be determined. The limited functional evidence available to date was generated in the mouse experimental model. ${ }^{11-13}$

\section{Tissue repair and implantation}

Barash et al., demonstrated that endometrial biopsies taken during the spontaneous cycle that preceded the in vitro fertilization (IVF) and embryo transfer (ET) treatment more than doubled the rates of implantation, clinical pregnancies and live births. ${ }^{14}$ Such favorable influence of local injury was later confirmed by Raziel et al., ${ }^{15}$ which showed a significant increase in the success of IVF/ET treatments in a population of patients with the previous implantation failures. A more recent study, further reported that local injury of the endometrium performed in IVF/ET patients during their cycle of treatment, before ovum retrieval, also resulted in increased success of implantation and pregnancy. ${ }^{16}$ Mechanical manipulation, which is associated with decidual formation is not a new phenomenon. In 1907, Leo Loeb ${ }^{17}$ first reported that scratching the guinea-pig uterus during the progestational phase of the estrous cycle provoked a rapid growth of decidual cells. Later experiments showed that decidua formation in pseudopregnant rodents could be induced by other forms of local injury, such as suturing the uterine horn ${ }^{18}$ and intra-uterine injection of oil. ${ }^{19}$ These early observations in rodents, combined with our recent findings in human patients, suggest that local injury of the endometrium facilitates successful implantation. Additionally, albeit indirect, evidence to support the beneficial effect of endometrial injury on successful implantation comes from the observation that scar tissue from previous endometrial surgery (or Cesarean section) becomes an attractive site of implantation. ${ }^{20}$ Taken together, these reports suggest that it is possible that the success of implantation is secondary to the development of an injury-induced inflammatory reaction.

\section{Immune cells and implantation}

A high level of the pro-inflammatory Thelper (Th)-1 and cytokines (IL-6, IL-8, and TNF $\alpha$ ) characterizes early implantation. ${ }^{21-23}$ These cytokines can be secreted by the endometrial cells as well as by cells of the immune system that are recruited to the site of implantation. Indeed the utero-placental unit of human and mice is richly populated with hemato-poietic cells. Of these, 65-70\% are uterine-specific natural killer (NK) cells, and 10-20\%, are antigen presenting cells (APC) such as macrophages (Mos) and dendritic cells (DCs). ${ }^{24-28}$ NK cells in human decidua have a role in regulating trophoblast invasion by the production of IL-8 and interferon-inducible protein-10 chemokines. Furthermore, decidual NK cells are potent secretors of an array of angiogenic factors that induce vascular growth that is essential for the establishment of an adequate decidua. ${ }^{29}$ DCs are an heterogenous population of cells that initiate and coordinate the innate adaptive immune response. These cells accumulate in the pregnant uterus prior to implantation and stay in the deciduas throughout pregnancy. ${ }^{30-32}$ Several lines of evidence point to a pivotal role of APC in shaping the cytokine profile at the maternal-fetal interface. ${ }^{29,30}$ Furthermore, a recent study from our laboratory showed that depletion of uterine DCs (uDCs) cells resulted in a sever 
impairment of implantation and led to embryo resorption. ${ }^{33}$ However, the effect observed in our study was not related to tolerance but rather to successful decidualization. In agreement with our findings, another study showed that therapy with DCs significantly decreased the spontaneous resorption rate in a mouse model. ${ }^{30}$ These studies, both suggest that, in addition to their involvement in the immune response, uDCs also play some tropic role in regulating pregnancy.

The immune infiltrate, that plays a central role in the process of tissue renewal and differentiation, may also participate in the development of a receptive endometrium in the biopsy-treated patients. In addition to their immediate influence, recruitment of cells of the immune system to the site of injury may create some 'tissue memory' facilitating implantation in the following cycle of treatment. In fact, monocyte precursors of Mos and DCs are known to be recruited to injured sites and provide essential beneficial effects during wound healing. These cells are long lived, and reside, in some tissues for months, during which time they can differentiate into tissue-resident Mos or DCs. ${ }^{34}$

\section{The trophoblast-lumen epithelium synapse}

As the blastocyst travels from the fallopian tube to the uterine cavity, the surface epithelium of the uterus functions as the first contact responsible for adequate attachment of the trophectoderm to the epithelium and the subsequent trophoblast invasion and placentation. When a mammalian blastocyst enters the uterine cavity, the surface epithelium of the uterus is covered by molecules, such as Mucin 1 (MUC1) carbohydrates, that prevent the attachment of the highly adhesive blastocyst to an improper site. Indeed, in the human endometrium MUC1 is upregulated during the implantation period. ${ }^{35,36}$ This suggests that the human endometrial surface epithelium prevents blastocyst adhesion, except for the precise spot where the embryo attaches. We hypothesize that cytokines/chemokines produced by DCs/Mos in the uterine stroma induce local degradation of MUC1, which enable the blastocyst to attach to a specific area of the uterus. There are four ways by which blastocysts binding to the epithelium may be enhanced: (i) stored adhesion molecules are rapidly moved to the cell surface; (ii) inflammation-induced expression of new adhesion molecules; (iii) increased affinity of specific molecules following initial cell contact; and (iv) reorganization of adhesion molecules on the surface epithelium (Fig. 1). Either of these possibilities or their combination can represent the response of the endometrial epithelium to DCs recruited to the site of implantation.

\section{Summary and relevance}

Many fertility disorders have been overcome by a variety of assisted reproductive techniques. Nevertheless, embryo implantation remains the rate-limiting step for the success of IVF. Attempts to maximize the chance of successful implantation include the transfer of more than a single embryo. This strategy results in a high incidence of multiple gestations, which is related to the number of embryos transferred. The rate of multiple gestations after IVF, in both Europe and the USA, is 26.4 and 35.4 percent, respectively and multiple birth pregnancies are the major cause for the increased risks of potential death and premature birth in IVF patients. Furthermore, restricted fetal growth, increased incidence of congenital malformations and greater likelihood of maternal complications has been reported as a consequence of multiple birth pregnancies. Deciphering the components that are associated with improved implantation can be employed for identifying new therapeutic targets and developing novel means to extend uterine receptivity. Furthermore, once an improved rate of successful implantation is achieved it may serve as a strong incentive for the use of single-embryo transfers, avoiding multiple birth pregnancies and their subsequent, often severe implications. Moreover, increasing the rate of pregnancy in IVF/ET programs will 
reduce the number of repeated cycles of treatment, thus lowering the possible risks associated with massive exposure to gonadotropins. Equally important, the information generated from studies associated with the inflammatory response during implantation will potentially define, hitherto unavailable, markers that will serve to predict low chances for successful implantation, further recommending that IVF may not always be the immediate solution.

\section{Acknowledgments}

This study was supported in part by a grant from the NICHD/NCI P011HD054713 (GM) and the Israel Ministry of Health (ND).

\section{References}

1. Wang H, Dey SK. Roadmap to embryo implantation: clues from mouse models. Nat Rev Genet 2006;7:185-199. [PubMed: 16485018]

2. Dunn CL, Kelly RW, Critchley HO. Decidualization of the human endometrial stromal cell: an enigmatic transformation. Reprod Biomed Online 2003;7:151-161. [PubMed: 14567882]

3. Paria BC, Das SK, Dey SK. Deciphering the cross-talk of implantation: advances and challenges. Science 2002;296:2185-2188. [PubMed: 12077405]

4. Dunn CL, Critchley HO. Decidualization of the human endometrial stromal cell: an enigmatic transformation. Reprod Biomed 2003;7:151-161.

5. Akbas GE. HOXC and HOXD gene expression in human endometrium: lack of redundancy with HOXA paralogs. Biol Reprod 2004;70:39-45. [PubMed: 12954737]

6. Kao LCTS, Lobo S, Imani B, Yang JP, Germeyer A, Osteen K, Taylor RN, Lessey BA, Giudice LC. Global gene profiling in human endometrium during the window of implantation. Endocrinology 2002;143:2119-2138. [PubMed: 12021176]

7. Popovici RM, Giudice LC. Discovery of new inducible genes in in vitro decidualized human endometrial stromal cells using microarray technology. Endocrinology 2000;141:3510-3513. [PubMed: 10965925]

8. Carson DD, Thathiah A, Al-Shami R, Farach-Carson MC, Vernon M, Yuan L, Fritz MA, Lessey B. Changes in gene expression during the early to mid-luteal (receptive phase) transition in human endometrium detected by high-density microarray screening. Mol Hum Reprod 2002;8:871-879. [PubMed: 12200466]

9. Dominguez F, Pellocer A, Simon C. Human endometrial receptivity: a genomic approach. Reprod Biomed Online 2003;6:332-338. [PubMed: 12735869]

10. Giudice L. Microarray expression profiling reveals candidate genes for human uterine receptivity. Am J Pharmacogenomics 2004;4:299-312. [PubMed: 15462608]

11. Riesewijk A, van OsR, Horcajadas JA, Polman J, Pellicer A, Mosselman S, Simón C. Gene expression profiling of human endometrial receptivity on days $\mathrm{LH}+2$ versus $\mathrm{LH}+7$ by microarray technology. Mol Hum Reprod 2003;9:253-264. [PubMed: 12728018]

12. Stewart CL, Kaspar P, Brunet LJ, Bhatt H, Gadi I, Kontgen F, Abbondanzo SJ. Blastocyst implantation depends on maternal expression of leukaemia inhibitory factor [see comments]. Nature 1992;359:76-79. [PubMed: 1522892]

13. Satokata I, Maas R. Sexually dimorphic sterility phenotypes in Hoxa10 deficient mice. Nature 1995;37:460-463. [PubMed: 7700356]

14. Barash A, Fieldust S, Segal I, Schechtman E, Granot I. Local injury of the endometriumdoubles the incidence of successful pregnancies in patients undergoing in-vitro fertilization. Fertil Steril 2003;79:1317-1322. [PubMed: 12798877]

15. Raziel A, Strassburger D, Berno O, Ron-El R, Friedler S. Favorable influence of local injury to the endometrium in intracytoplasmic sperm injection patients with high-order implantation failure. Fertil Steril 2007;87:198-201. [PubMed: 17197286] 
16. Zhou L, Wang R, Huang HX, Zhong K. Local injury to the endometrium in controlled ovarian hyperstimulation cycles improves implantation rates. Fertil Steril 2008;89:1166-1176. [PubMed: 17681303]

17. Loeb L. Ueber die experimentelle Erzeugung von Knoten von Deciduagewebe in dem Uterus des Meerschweinchens nach stattgefundener. Copulation Zentralbl AlIg Pathol Pathol Anat 1907;18:563-565.

18. Turner, CD. Biological effects of the ovarian hormones. In: Saunders, WB., editor. General Endocrinology. 6. Philadelphia, Pennsylvania: 1976. p. 466-476.

19. Saito, S.; Sasaki, Y. Th1/Th2 balance at implantation stage. In: Mor, G., editor. Immunology of Pregnancy. New York, New York: 2006. p. 37-48.

20. Dominguez F, Yanez-Mo M, Sanchez-Madrid F, Simon C. Embryonic implantation and leukocyte transendothelial migration: different processes with similar players? FASEB J 2005;19:10561060. [PubMed: 15985528]

21. Koga K, Mor G. Expression and function of toll-like receptors at the maternal-fetal interface. Reprod Sci 2008;15:231-242. [PubMed: 18421019]

22. Mor G, Koga K. Macrophages and pregnancy. Reprod Sci 2008;15:435-436. [PubMed: 18579852]

23. Yoshinaga K. Review of factors essential for blastocyst implantation for their modulating effects on the maternal immune system. Semin Cell Dev Biol 2008;19:161-169. [PubMed: 18054836]

24. Hanna JG, Hamani Y, Avraham I, Greenfield C, Natanson-Yaron S, Prus D, Cohen-Daniel L, Arnon TI, Manaster I, Gazit R, Yutkin V, Benharroch D, Porgador A, Keshet E, Yagel S, Mandelboim O. Decidual NK cells regulate key developmental processes at the human fetalmaternal interface. Nat Med 2006;12:1065-1074. [PubMed: 16892062]

25. Kammerer, U.; Rieger, L.; Honig, A.; Kampgen, E. Characterization of Human Dendritic Cells at the Materno-fetal Interface. Georgetown, Texas: Landes Bioscience/Springer Science; 2006.

26. Abrahams VM, Kim YM, Straszewski SL, Romero R, Mor G. Macrophages and apoptotic cell clearance during pregnancy. Am J Reprod Immunol 2004;51:275-282. [PubMed: 15212680]

27. Roussev RG, Acacio B, Ng SC, Coulam CB. Duration of intralipid's suppressive effect on NK cell's functional activity. Am J Reprod Immunol 2008;60:258-263. [PubMed: 18782287]

28. Le Bouteiller P, Piccinni MP. Human NK cells in pregnant uterus: why there? Am J Reprod Immunol 2008;59:401-406. [PubMed: 18405310]

29. Mor G. Inflammation and pregnancy: the role of tolllike receptors in trophoblast-immune interaction. Ann N Y Acad Sci 2008;1127:121-128. [PubMed: 18443339]

30. Laskarin G, Rukavina D, Thomson AW, Fernandez N, Blois SM. Antigen-presenting cells and materno-fetal tolerance: an emerging role for dendritic cells. Am J Reprod Immunol 2007;58:255267. [PubMed: 17681042]

31. Kämmerer U. Antigen-presenting cells in the decidua. Chem Immunol Allergy 2005;89:96-104. [PubMed: 16129956]

32. Scholz C, Toth B, Brunnhuber R, Rampf E, Weissenbacher T, Santoso L, Friese K, Jeschke U. Glycodelin A induces a tolerogenic phenotype in monocyte-derived dendritic cells in vitro. Am J Reprod Immunol 2008;60:501-512. [PubMed: 19032611]

33. Plaks V, Birnberg T, Berkutzki T, Sela S, BenYashar A, Kalchenko V, Mor G, Keshet E, Dekel N, Neeman M, Jung S. Uterine DCs are crucial for decidua formation during embryo implantation in mice. J Clin Invest 2008;118:3954-3965. [PubMed: 19033665]

34. Luster AD, von Andrian UH. Immune cell migration in inflammation: present and future therapeutic targets. Nat Immunol 2005;6:1182-1190. [PubMed: 16369557]

35. Meseguer M, Aplin JD, Caballero-Campo P, O’Connor JE, Martin JC, Remohi J, Pellicer A, Simon C. Human endometrial mucin MUC1 is up-regulated by progesterone and down-regulated in vitro by the human blastocyst. Biol Reprod 2001;64:590-601. [PubMed: 11159362]

36. Simon C, Martin JC, Meseguer M, Caballero-Campo P, Valbuena D, Pellicer A. Embryonic regulation of endometrial molecules in human implantation. J Reprod Fertil Suppl 2000;55:43-53. [PubMed: 10889833] 


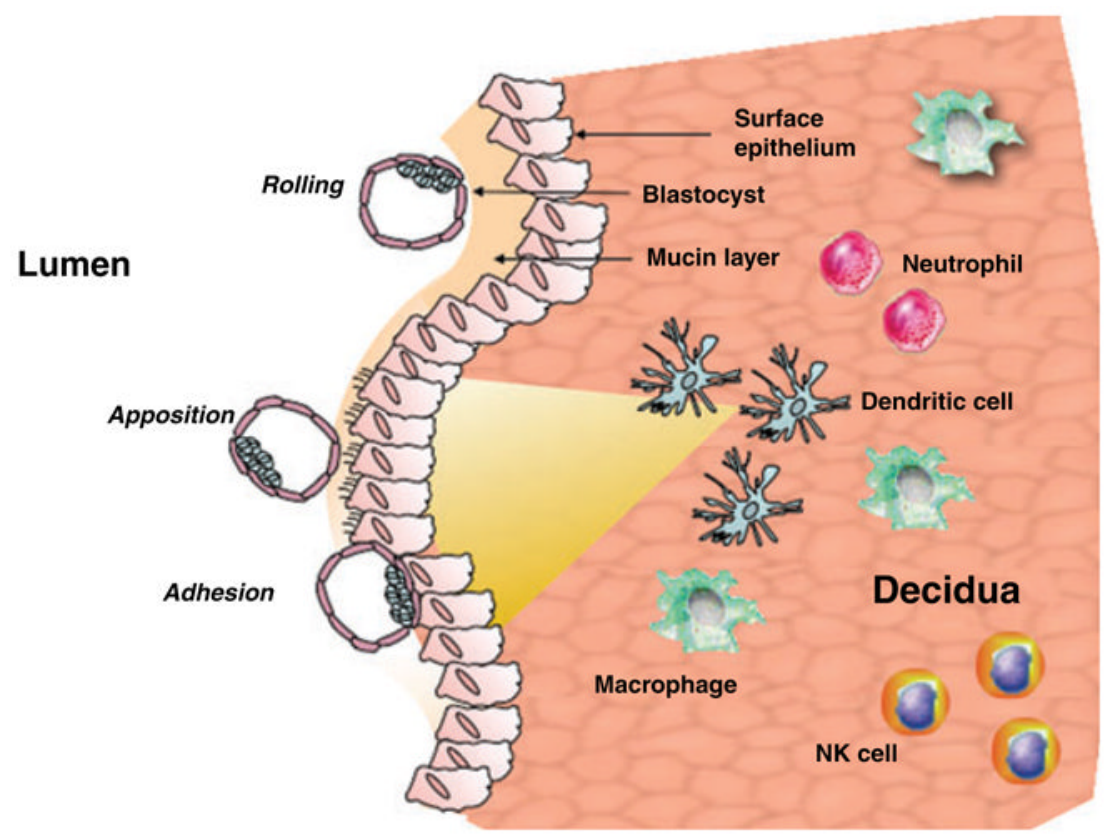

Fig. 1.

Dendritic cells and macrophages create an inflammatory gradient which affects on the epithelium the expression of the mucin layer and increases the expression of ligands for adhesion molecules expressed by the blastocyst. The inflammatory gradient allows the apposition and adhesion of the blastocyst to the epithelium and promotes implantation. 